\title{
LEMPUNG TERPILAR SILIKA UNTUK PENGHILANGAN FENOL DALAM AIR
}

\author{
Adi Darmawan, Choiril Azmiyawati dan Pulojuliadi Nababan \\ Laboratorium Kimia Anorganik Universitas Diponegoro
}

\begin{abstract}
ABSTRAK
Limbah fenol dapat mencemari lingkungan, namun pengolahan limbah fenol masih memiliki banyak kendala. Kendala disebabkan proses pengolahan yang menggunakan prinsip flokulasi dan koagulasi dengan biaya instalasi dan operasional yang mahal. Menanggapi kendala tersebut lempung terpilar $\mathrm{SiO}_{2}$ mampu digunakan sebagai katalis oksidasi fenol dalam air limbah.

Lempung terpilar SiO2 memiliki basal spacing, luas permukaan besar, dan stabil pada temperatur tinggi. Sintesis lempung terpilar SiO2 melalui proses interkalasi TEOS (tetraetilortosilikat) dan surfaktan dodesilamin pada daerah antarlapis lempung. Lempung terpilar SiO2 diimpregnasi dengan menggunakan logam nikel. Proses sintesis lempung terpilar SiO2 dikarakterisasi menggunakan metode difraktometer sinar X dalam menentukan kenaikan basal spacing dan kristalinitas. Penentuan aktivitas katalis lempung terpilar SiO2/Ni terhadap konversi oksidasi fenol dalam air limbah menggunakan spektrofotometri UV-Visible.

Lempung terpilar tanpa kalsinasi mengasilkan basal spacing 28,55 A sedangkan lempung terpilar $\mathrm{SiO} 2$ kalsinasi 600 OC menghasilkan basal spacing 27,77 $\mathrm{A}$. Aplikasi lempung terpilar SiO2/Ni sebagai katalis oksidasi fenol dalam air limbah mampu mengkonversi limbah fenol hingga mencapai $70 \%$. Aktivitas katalis SiO2 optimalisasi pada konsentrasi nikel yang teremban $4 \%$, dimana semakin banyak nikel yang teremban pada lempung terpilar SiO2 maka aktivitas katalisisnya semakin meningkat
\end{abstract}

Kata Kunci: Lempung Terpilar SiO2, fenol, adsorpsi

\section{PENDAHULUAN}

Proses kimia yang menghasilkan limbah fenol sangat berbahaya bagi lingkungan sekitarnya, karena fenol merupakan senyawa organik yang toksik. Kadar fenol dalam air limbah perlu diminimalkan untuk mengurangi pencemaran terhadap lingkungan. Pengolahan terhadap limbah fenol yang pernah dilakukan adalah melalui proses filtrasi dan proses adsorpsi dengan prinsip flokulasi dan koagulasi menggunakan karbon aktif untuk menyisihkan senyawa aromatik seperti fenol dan senyawa organik terlarut lainnya. Pengolahan limbah melalui proses filtrasi tersebut menggunakan teknologi membran atau reserve osmosis dan menggunakan reaktor yang membutuhkan biaya instalasi dan operasional yang sangat mahal (Warlina, 1985).
Lempung sebagai material yang mempunyai lapisan yang dapat mengembang sampai saat ini belum optimal dalam pemanfaatannya. Pada dasarnya struktur pori dari material lempung tidak permanen sehingga perlu dilakukan pemilaran pada daerah antarlapis lempung. Lempung terpilar dapat diperoleh dengan menginterkalasikan oksida logam, kation organik, atau surfaktan pada daerah antarlapis lempung yang akan menghasilkan pilar dan struktur pori yang stabil sehingga dapat digunakan sebagai adsorben ataupun katalis (Vansant dan Cool, 1997).

Sintesis lempung terpilar melalui interkalasi pada daerah antarlapis lempung yang telah dibuat antara lain adalah sintesis lempung terpilar $\mathrm{SiO}_{2} / \mathrm{Ni}$ dengan basal spacing 29,31 , luas permukaan 336,52 $\mathrm{m}^{2} / \mathrm{g}$, dan karakter 
keasaman pada permukaan lapisan mencapai $400-800 \mathrm{~cm}^{-1}$, sehingga mampu digunakan sebagai katalis dalam reaksi reformasi gas $\mathrm{CO}_{2}$. Katalis lempung terpilar $\mathrm{SiO}_{2} / \mathrm{Ni}$ mampu mempercepat reaksi reformasi $\mathrm{CO}_{2}$ dengan persentase kecepatan pembentukan mencapai $78,63 \%-92,48 \%$ relatif terhadap reaksi tanpa katalis lempung terpilar (Gozan, 2001).

Dalam penelitian ini akan dikaji proses sintesis lempung terpilar $\mathrm{SiO}_{2}$ dari lempung alam dan uji aktivitasnya sebagai katalis oksidasi fenol dalam air limbah. Lempung diinterkalasi menggunakan TEOS dengan bantuan kosurfaktan dodesilamin yang bertujuan untuk memperbesar jarak daerah antarlapis lempung, sehingga akan dihasilkan lempung terpilar $\mathrm{SiO}_{2}$ yang stabil (Pinnavaia dan Poleverjan, 2000). Dalam penelitian ini dilakukan impregnasi logam nikel dengan variasi konsentasi $0,5 \%, 1 \%, 2 \%$, dan $4 \%$ (b/b) yang diharapkan dapat terdistribusi merata pada daerah antarlapis lempung untuk meningkat aktivitas katalis.

Sintesis lempung terpilar $\mathrm{SiO}_{2} / \mathrm{Ni}$ diharapkan dapat digunakan sebagai katalis dalam proses oksidasi fenol dalam air limbah serta mampu memberikan solusi baru metode pengolahan limbah fenol, sehingga dapat meminimalkan pencemaran terhadap lingkungan.

\section{METODE PENELITIAN}

Peralatan: Peralatan yang digunakan dalam penelitian ini adalah peralatan gelas, magnetic strirer/hot plate, oven, furnace atau tungku kalsinasi, ayakan material 200 mesh, timbangan analitis, vibrator aliran udara, difraktometer sinar X Shimadzhu X-2700, dan spektrofotometri UV-Visible Secoman 1500 PC.
Bahan: Bahan-bahan yang digunakan dalam penelitian ini adalah lempung alam yang telah lolos ayakan 200 mesh, dodesilamina, amonium hidroksida, akuades, $\mathrm{NiCl}_{2} .6 \mathrm{H}_{2} \mathrm{O}$, amonium klorida, 4-AAP (4-aminoantipirin), kloroform, kalium ferrisianida, sampel limbah fenol, etanol, dan TEOS (tetraetilortosilikat).

\section{Prosedur Kerja}

Sintesis Lempung Terpilar: Lempung sebanyak 5 gram dilarutkan dalam campuran TEOS-dodesilamin dengan perbandingan molar TEOS:dodesilamin adalah 10:2. Volume TEOS dan dodesilamin yang digunakan masing-masing adalah $25 \mathrm{~mL}$ dan $5 \mathrm{~mL}$. Campuran diaduk pada temperatur kamar $\left( \pm 27^{\circ} \mathrm{C}\right)$ selama 5 jam, kemudian lempung terinterkalasi yang diperoleh disaring dan dicuci dengan etanol untuk menghilangkan sisa surfaktan. Lempung terinterkalasi dikeringkan di udara terbuka pada temperatur kamar sebelum dikalsinasi pada temperatur $600^{\circ} \mathrm{C}$ dengan kecepatan kenaikan temperatur $2^{\circ} \mathrm{C} /$ menit, selama 2 jam untuk memperoleh lempung terpilar $\mathrm{SiO}_{2}$.

\section{Impregnasi Nikel pada Lempung Terpilar}

Larutan impregnasi dibuat dengan melarutkan $\mathrm{NiCl}_{2} \cdot 6 \mathrm{H}_{2} \mathrm{O}$ dalam $10 \mathrm{~mL}$ air dengan variasi kandungan logam nikel $0,5 \% ; 1 \% ; 2 \% ; 4 \%$ dari berat lempung terpilar yang akan diimpregnasi.

Lempung terpilar ditambahkan dalam larutan impregnasi $\mathrm{NiCl}_{2} \cdot 6 \mathrm{H}_{2} \mathrm{O}$ dan diaduk selama 2,5 jam pada temperatur kamar. Lempung dikeringkan dalam oven pada temperatur $110^{\circ} \mathrm{C}$ selama 30 menit. Lempung yang diperoleh dikalsinasi pada temperatur $400^{\circ} \mathrm{C}$ dengan kecepatan kenaikan temperatur $2^{\circ} \mathrm{C} /$ menit, selama 2 jam untuk memperoleh katalis lempung terpilar $\mathrm{SiO}_{2}$ teremban nikel $\left(\mathrm{SiO}_{2} / \mathrm{Ni}\right)$. 
Karakterisasi Lempung Terpilar dengan Penentuan Basal Spacing

Penentuan basal spacing dilakukan dengan menggunakan difraktometer sinar X Shimadzhu $\mathrm{X}-2700$ dengan metode bubuk menggunakan target $\mathrm{Cu}$ dan kecepatan pengukuran $2 \%$ menit. Lempung asli, lempung terpilar, dan lempung tanpa kalsinasi dilakukan pengukuran pada daerah $2 \theta=2^{\circ}-15^{\circ}$.

\section{Aplikasi dan Uji Aktivitas Katalis}

Fenol sebanyak 5 mg dilarutkan dalam 100 mL air dan dimasukkan dalam tabung gelas, kemudian untuk proses oksidasi ditambahkan 0,2 gram bubuk katalis lempung terpilar $\mathrm{SiO}_{2}$ dengan variasi nikel teremban $0,5 \% ; 1 \% ; 2 \%$; $4 \%$. Sebagai standar pembanding oksidasi fenol dilakukan tanpa menggunakan katalis. Proses oksidasi dilakukan dengan menggunakan aliran udara dari vibrator selama 4 jam. Konversi oksidasi fenol dianalisis dengan menggunakan spektrofotometri UV-Visible Secoman 1500 PC.

\section{HASIL DAN PEMBAHASAN}

\section{Sintesis Lempung Terpilar Silika}

Proses sintesis lempung terpilar $\mathrm{SiO}_{2}$ dari lempung alam melalui dua tahap reaksi. Tahap pertama adalah interkalasi TEOS-dosesilamin pada daerah antarlapis lempung, dan tahap kedua merupakan proses kalsinasi lempung terinterkalasi untuk mengubah TEOS menjadi pilar silika. Proses interkalasi TEOS pada daerah antarlapis lempung dibantu dengan penambahan surfaktan dodesilamin. Penambahan surfaktan dodesilamin pada daerah antarlapis lempung bertujuan untuk memperbesar jarak antarlapis lempung, sehingga akan mempermudah proses interkalasi TEOS pada daerah antarlapis lempung.

Semakin besar jarak antarlapis lempung maka akan semakin mudah TEOS yang masuk pada daerah antarlapis lempung, sehingga akan berpengaruh terhadap perubahan basal spacing yang dihasilkan. Proses interkalasi TEOSdodesilamin pada daerah antarlapis lempung menghasilkan cairan kental berwarna keabuan yang menunjukkan bahwa proses interkalasi TEOS dan dodesilamin pada daerah antarlapis lempung berlangsung secara spontan pada temperatur kamar (Kwon dkk., 2000). Penggunaan TEOS berlebihan dengan perbandingan TEOS:dodesilamin adalah 10:2, bertujuan untuk dapat melarutkan surfaktan dodesilamin serta menyediakan sumber silika yang cukup dalam pembentukan pilar siloksan yang stabil pada temperatur tinggi. Dodesilamin yang terlarut dalam TEOS akan mempermudah interkalasi TEOS, karena dodesilamin tersebut membantu memperbesar jarak antar lapis lempung. Jika konsentrasi TEOS yang digunakan kecil maka pilar siloksan yang terbentuk akan lemah, karena jumlah TEOS yang digunakan tidak sebanding dengan surfaktan dodesilamin, sehingga akan mempengaruhi terhadap pergeseran jarak antarlapis lempung.

Kalsinasi pada temperatur tinggi bertujuan untuk menghilangkan surfaktan dan pilar siloksan tersebut, sehingga pada daerah antarlapis lempung tidak terbentuk pilar (Kwon dkk., 2000). Kalsinasi pada temperatur $600^{\circ} \mathrm{C}$ bertujuan untuk menghilangkan sisa-sisa surfaktan yang digunakan selama proses pemilaran dan menyempurnakan reaksi dehidroksilasi siloksan menjadi pilar oksida 
silika $\left(\mathrm{SiO}_{2}\right)$ yang stabil dan permanen. TEOS pada temperatur $600^{\circ} \mathrm{C}$ teroksidasi menjadi oksida silika $\mathrm{SiO}_{2}$ dengan disertai pelepasan molekul air.

Menurut Pinnavaia, dkk., (1997), perubahan TEOS menjadi oksida silika $\mathrm{SiO}_{2}$ dapat berlangsung pada temperatur $300-550^{\circ} \mathrm{C}$. Namun kalsinasi pada temperatur $550^{\circ} \mathrm{C}$ masih menyisakan senyawa organik yang ditandai dengan terbentuknya warna hitam dari lempung yang telah terkalsinasi. Masih tersisanya senyawa organik tersebut disebabkan karena penggunaan TEOS dan dodesilamin yang berlebihan. Penggunaan TEOS dan dodesilamin yang berlebihan menyebabkan semakin banyak zat organik pada daerah antarlapis yang berasal dari produk samping reaksi dehidroksilasi TEOS dan surfaktan yang digunakan, sehingga diperlukan pemanasan yang lebih tinggi untuk menghilangkan sisa-sisa zat organik tersebut. Keberadaan senyawa organik di dalam pori mempengaruhi aktivitas katalis karena pori yang terbentuk akan terisi oleh senyawa-senyawa organik dari sisa-sisa surfaktan maupun produk samping reaksi dehidroksilasi TEOS. Semakin tinggi temperatur kalsinasi, maka akan semakin menyempurnakan proses dehidroksilasi TEOS dan menghilangkan semua sisa-sisa surfaktan yang digunakan, sehingga luas permukaan yang dihasilkan semakin besar (Pinnavaia dkk., 1997).

Kalsinasi lempung terpilar $\mathrm{SiO}_{2}$ pada temperatur $600^{\circ} \mathrm{C}$ mengakibatkan TEOS teroksidasi menjadi oksida silika yang disertai dengan pelepasan molekul air serta menghilangkan sisa surfaktan dodesilamin yang digunakan sehingga akan memperbesar permukaan pada daerah antarlapis lempung.
$\mathrm{Si}\left(\mathrm{OC}_{2} \mathrm{H}_{5}\right)_{4}+12 \mathrm{O}_{2} \longrightarrow \mathrm{SiO}_{2}+8 \mathrm{CO}_{2}+10 \mathrm{H}_{2} \mathrm{O}$

$2 \mathrm{H}_{2} \mathrm{NC}_{12} \mathrm{H}_{25}+40 \mathrm{O}_{2} \longrightarrow 24 \mathrm{CO}_{2}+27 \mathrm{H}_{2} \mathrm{O}+\mathrm{N}_{2} \mathrm{O}_{5}$

Pada reaksi tersebut, ion $\mathrm{H}^{+}$yang dibebaskan selama proses kalsinasi lempung terpilar pada temperatur $600^{\circ} \mathrm{C}$ mampu menyeimbangkan pada lapisan lempung sehingga menghasilkan pilar yang lebih stabil pada temperatur tinggi (Pinnavaia dkk., 1997).

\section{Karakterisasi Lempung Terpilar $\mathrm{SiO}_{2}$ meliputi basal spacing dan kristalinitas}

Proses pemilaran TEOS dan dodesilamin pada daerah antarlapis lempung akan menghasilkan pilar silika $\mathrm{SiO}_{2}$. Perubahan yang terjadi pada daerah antarlapis lempung dengan terbentuknya pilar $\mathrm{SiO}_{2}$ meliputi pertambahan basal spacing dan kristalinitas permukaan yang diidentifikasi menggunakan difraktometer sinar X shimadzhu X2700. Pola perubahan difraktogram menggunakan XRD ditentukan pada pergeseran puncak pada daerah $2 \theta=2^{\circ}-15^{\circ}$. Pola difraktogram pergeseran puncak dari lempung alam, lempung terpilar $\mathrm{SiO}_{2}$ tanpa kalsinasi, dan lempung terpilar $\mathrm{SiO}_{2}$ kalsinasi pada temperatur $600{ }^{\circ} \mathrm{C}$ yang muncul pada analisa XRD dapat dijelaskan pada Gambar 1 sebagai berikut.

Dari Gambar 1 dapat dilihat pola difraktogram yang dihasilkan terjadi pergeseran puncak pada lempung alam, terhadap lempung terpilar tanpa kalsinasi, dan lempung terpilar kalsinasi $600^{\circ} \mathrm{C}$. Pergeseran puncak pada lempung alam dari $2 \theta=\sim 5,67^{\circ}$ menjadi $2 \theta=\sim 3,09^{\circ}$ pada lempung terpilar tanpa kalsinasi, sedangkan pada lempung terpilar kalsinasi $600^{\circ} \mathrm{C}$ pergeseran puncak terjadi pada $2 \theta=\sim 3,17^{\circ}$. Pergeseran puncak dari $2 \theta=\sim 5,67^{\circ}$ pada lempung alam menunjukkan terbentuknya pilar $\mathrm{SiO}_{2}$ pada daerah antarlapis lempung yang diperlihatkan 
penurunan $2 \theta=\sim 3,17^{\circ}$ pada lempung terpilar $\mathrm{SiO}_{2}$ kalsinasi $600^{\circ} \mathrm{C}$.

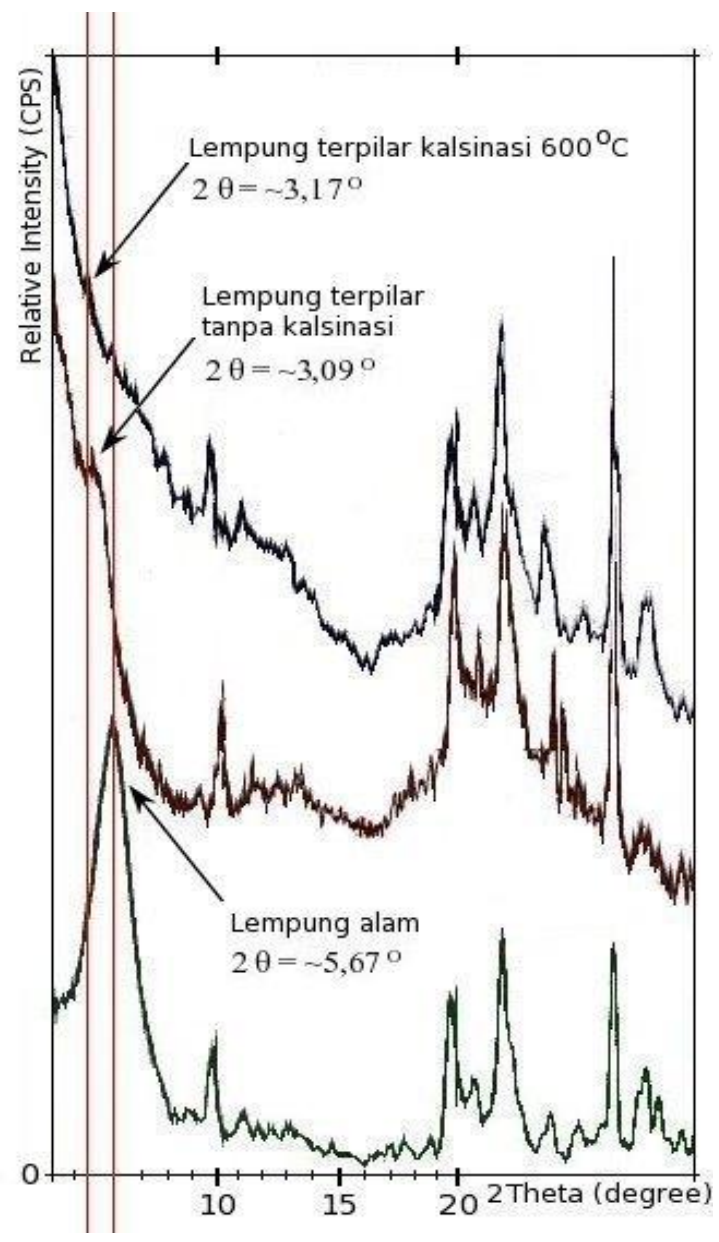

Gambar 1. Pola difraktogram lempung alam, lempung terpilar $\mathrm{SiO}_{2}$ tanpa kalsinasi, dan lempung terpilar $\mathrm{SiO}_{2}$ kalsinasi $600^{\circ} \mathrm{C}$

Pemanasan pada temperatur yang tinggi menyebabkan proses dekomposisi sebagian pilar silika yang telah terbentuk, sehingga menyebabkan sebagian puncak tidak muncul, disamping itu penambahan TEOS dan surfaktan dodesilamin yang berlebihan menyebabkan lemahnya puncak yang dihasilkan dimana TEOS dan dosesilamin yang berlebihan menyebabkan tertutupnya daerah antarlapis lempung karena molekul TEOS dan dodesilamin tidak tersusun secara teratur pada daerah antarlapis lempung (Pinnavaia dkk., 1997). Perubahan basal spacing pada lempung alam, lempung terpilar tanpa kalsinasi $\mathrm{SiO}_{2}$, dan lempung terpilar $\mathrm{SiO}_{2}$ kalsinasi $600{ }^{\circ} \mathrm{C}$ dapat dilihat pada Tabel 1 sebagai berikut.

Tabel 1. Basal spacing pada lempung alam, lempung terpilar tanpa kalsinasi $\mathrm{SiO}_{2}$, dan lempung terpilar $\mathrm{SiO}_{2}$ kalsinasi $600^{\circ} \mathrm{C}$

\begin{tabular}{|l|c|}
\hline Jenis material & Basal spacing $(\AA)$ \\
\hline Lempung alam & 15,54 \\
\hline $\begin{array}{l}\text { Lempung terpilar } \\
\text { tanpa kalsinasi } \mathrm{SiO}_{2}\end{array}$ & 28,55 \\
\hline $\begin{array}{l}\mathrm{Lempung} \text { terpilar } \\
\mathrm{SiO}_{2} \text { kalsinasi } 600^{\circ} \mathrm{C}\end{array}$ & 27,77 \\
\hline
\end{tabular}

Diperoleh data bahwa basal spacing lempung alam meningkat sebesar $13 \AA$, sedangkan penurunan basal spacing terjadi pada lempung terpilar $\mathrm{SiO}_{2}$ kalsinasi pada temperatur $600^{\circ} \mathrm{C}$ menurun sebesar 0,78-1 $\AA$ terhadap lempung terpilar $\mathrm{SiO}_{2}$ tanpa kalsinasi. Penurunan basal spacing pada lempung terpilar dapat dipengaruhi oleh reaksi stoikiometri terhadap perbandingan TEOS dan surfaktan dodesilamin.

Penurunan basal spacing juga dipengaruhi dengan hilangnya sisa-sisa senyawa organik sebagai produk samping reaksi dehidroksilasi TEOS dan surfaktan dodesilamin sebagai cetakan misel selama proses kalsinasi. Pernyataan ini sesuai dengan penelitian Kwon dkk., (2000) yang menyatakan bahwa penurunan basal spacing untuk lempung terpilar antara 3-5 $\AA ̊$ A pada kalsinasi temperatur $538^{\circ} \mathrm{C}$.

Perbedaan temperatur kalsinasi mempengaruhi pergeseran basal spacing dan kristalinitas dari lempung terpilar yang dihasilkan. Perbedaan tingkat ketajaman puncak yang dihasilkan antara lempung alam yaitu $15,54 \AA$ dengan lempung terpilar $\mathrm{SiO}_{2}$ kalsinasi $600^{\circ} \mathrm{C}$ pada yaitu $27,77 \AA$ memperlihatkan perubahan kristalinitas selama proses pilarisasi pada daerah antarlapis lempung. 
Proses pemilaran akan menurunkan kristalinitas daripada lempung alam, sebagai asumsi bahwa kristalinitas lempung alam adalah sebesar $100 \%$. Kristalinitas dari lempung terpilar $\mathrm{SiO}_{2}$ tanpa kalsinasi adalah sebesar $56,61 \%$ relatif terhadap lempung alam, sedangkan kristalinitas dari lempung terpilar $\mathrm{SiO}_{2}$ kalsinasi $600^{\circ} \mathrm{C}$ adalah sebesar 47,19\% relatif terhadap lempung alam. Perbandingan persentase kristalinitas terjadi penurunan dari lempung terpilar $\mathrm{SiO}_{2}$ tanpa kalsinasi terhadap lempung terpilar $\mathrm{SiO}_{2}$ kalsinasi $600^{\circ} \mathrm{C}$ adalah sebesar $9,42 \%$, terjadinya penurunan kristalinitas dipengaruhi pemanasan pada temperatur yang tinggi sehingga yang menyebabkan terjadi penataulangan struktur pilar silika yang terbentuk selama kalsinasi berlangsung.

Berkurangnya ketajaman puncak pada lempung terpilar $\mathrm{SiO}_{2}$ kalsinasi pada temperatur $600^{\circ} \mathrm{C}$ menunjukkkan terjadi penurunan kristalinitas pada daerah antarlapis lempung terpilar $\mathrm{SiO}_{2}$. Perubahan jarak daerah antarlapis lempung terhadap pembentukan pilar silika $\left(\mathrm{SiO}_{2}\right)$ pada daerah antarlapis adalah sebesar $\sim 12,23 \AA$. Peningkatan jarak daerah antarlapis yang cukup signifikan jika dibandingkan terhadap lempung alam. Peningkatan jarak antarlapis lempung tersebut dimungkinkan karena perbandingan rasio antara pemilar TEOS dan surfaktan dodesilamin mampu melakukan pembentukan misel pada daerah antarlapis lempung dan memperbesar jarak antarlapis lempung (Kwon dkk., 1998).

\section{Aplikasi Lempung Terpilar $\mathrm{SiO}_{2} / \mathrm{Ni}$ Katalis Oksidasi Fenol dalam Air Limbah}

Aplikasi katalis lempung terpilar $\mathrm{SiO}_{2} / \mathrm{Ni}$ dioptimalkan pada pemanfaatan terhadap oksidasi fenol dalam air limbah. Kemampuan konversi katalis lempung terpilar $\mathrm{SiO}_{2} / \mathrm{Ni}$ untuk mengoksidasi fenol dalam air limbah dengan variasi impregnasi logam nikel yang teremban dapat dilihat pada Tabel 2 sebelum dan sesudah oksidasi sebagai berikut.

Tabel 1. Hasil perhitungan oksidasi fenol dalam air limbah variasi katalis

\begin{tabular}{|c|c|c|c|c|}
\hline $\begin{array}{c}\text { Katalis } \\
\mathrm{SiO}_{2} / \mathrm{Ni}\end{array}$ & $\begin{array}{c}\text { Konsentrasi } \\
\text { fenol awal } \\
(\mathrm{ppm})\end{array}$ & $\begin{array}{c}\text { Konsentrasi } \\
\text { fenol hilang } \\
(\mathrm{ppm})\end{array}$ & $\begin{array}{c}\text { Konsentrasi } \\
\text { fenol sisa } \\
(\mathrm{ppm})\end{array}$ & $\begin{array}{c}\text { Absorbansi } \\
(\AA)\end{array}$ \\
\hline 0 & 50 & 41,073 & 8,927 & 0,720 \\
\hline $0,5 \%$ & 50 & 41,176 & 8,824 & 0,712 \\
\hline $1 \%$ & 50 & 41,498 & 8,502 & 0,687 \\
\hline $2 \%$ & 50 & 41,730 & 8,270 & 0,669 \\
\hline $4 \%$ & 50 & 42,000 & 8,000 & 0,640 \\
\hline
\end{tabular}

Berkurangnya konsentrasi fenol dalam air limbah menunjukkan aktivitas dari katalis $\mathrm{SiO}_{2} / \mathrm{Ni}$ tersebut. Perubahan konsentrasi fenol dalam air limbah sebelum dan sesudah proses oksidasi dapat ditingkatkan dengan adanya impregnasi logam nikel dalam pori lempung terpilar yang mampu meningkatkan aktivitas katalisisnya. Hal tersebut dapat terlihat dari oksidasi fenol dalam air limbah tanpa menggunakan katalis menghasilkan konsetrasi sisa fenol 8,927 ppm, dibandingkan dengan katalis teremban nikel $0,5 \%$ menghasilkan konsentrasi sisa fenol 8,824 ppm. Semakin banyak impregnasi logam nikel dalam pori lempung akan meningkatkan aktivitas katalis dalam mengoksidasi fenol dalam air limbah, hal ini dapat dilihat dari peningkatan konsentrasi sisa fenol yang dihasilkan terhadap katalis impregnasi nikel $0,5 \%, 1 \%, 2 \%$, dan $4 \%$ dalam reaksi selama 4 jam pada temperatur kamar. Optimalisasi berada pada katalis $\mathrm{SiO}_{2}$ teremban 
$4 \%$ dimana menghasilkan sisa fenol 8,000 ppm, perbandingan katalis $\mathrm{SiO}_{2} / \mathrm{Ni}$ variasi nikel teremban $0,5 \%, 1 \%, 2 \%$, dan $4 \%$ mencapai $\approx$ 0,232 ppm terhadap oksidasi fenol tanpa menggunakan katalis lempung terpilar $\mathrm{SiO}_{2} / \mathrm{Ni}$. Peningkatan aktivitas katalis $\mathrm{SiO}_{2}$ variasi logam nikel teremban terhadap oksidasi fenol dalam air limbah dapat dilihat pada Gambar 4.1 sebagai berikut.

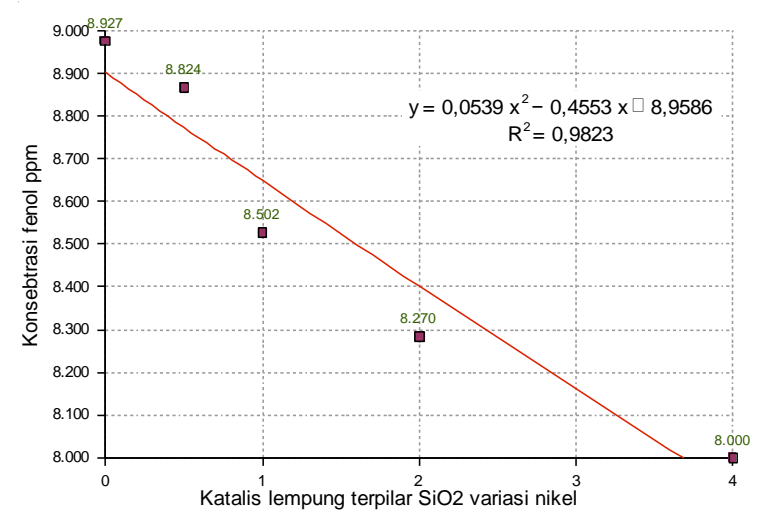

Gambar 2. Konversi fenol dalam air limbah terhadap variasi katalis $\mathrm{SiO}_{2} / \mathrm{Ni}$

Secara umum bertambahnya konsentrasi nikel yang teremban mampu meningkatkan aktivitas katalis tersebut. Pada kondisi lain aktivitas oksidasi tanpa menggunakan katalis relatif lebih rendah dibandingkan dengan oksidasi menggunakan katalis oksidasi lempung terpilar $\mathrm{SiO}_{2} / \mathrm{Ni}$ dengan variasi nikel yang teremban. Konsentrasi impregnasi logam nikel yang berlebihan dapat menyebabkan distribusi nikel kurang merata jika dibandingkan terhadap jumlah pori dari lempung terpilar yang akan memungkinkan tertutupnya pori dan mengurangi aktivitas katalis tersebut.

\section{KESIMPULAN}

Sintesis lempung terpilar $\mathrm{SiO}_{2}$ dari lempung alam dapat dilakukan melalui interkalasi TEOSdodesilamin pada daerah antarlapis Lampung. Lempung terpilar yang dihasilkan memiliki basal spacing $27,77 \AA$ dan stabil pada temperatur $600^{\circ} \mathrm{C}$. Lempung terpilar $\mathrm{SiO}_{2}$ teremban nikel dapat digunakan sebagai katalis oksidasi fenol dalam air limbah. Semakin besar konsentrasi nikel yang teremban pada lempung terpilar $\mathrm{SiO}_{2}$ maka aktivitas katalisisnya semakin bertambah dan optimum pada konsentasi $\mathrm{SiO}_{2} / \mathrm{Ni} 4 \%$.

\section{DAFTAR PUSTAKA}

Gozan, M. S., 2001., Aktivasi, Karakterisasi, Preparasi, dan Uji Aktivitas Lempung Terpilar $\mathrm{SiO}_{2} / \mathrm{Ni}, \mathrm{AlPO}_{4}, \mathrm{Al}_{3} \mathrm{Ti}$, dan $\mathrm{TiO}_{2}$ Aplikasi Katalis Reaksi Reformasi Gas $\mathrm{CO}_{2}$, Departemen Teknik Gas dan Petrokimia, Fakultas Teknik Universitas Indonesia, tidak dipublikasikan, Depok 2, 16424, 442-524

Kwon, Oh-Yun Shin., Hak-sik, Choi., SangWon., 2000, Preparations of Porous Silica Pillared Layared Phase; Simultaneous Intercalations of Amine Tetraethylorthosilicate into the $\mathrm{H}^{+}-$ maganidi and Intragallery Amine Catalyzed Hydrolisys of Tetraethylorthosilicate, Korean Chem. Matter., 12, 1273-1278

Pinnavaia dan Poleverjan, 2000., Intercalated Clay Catalysts, Chem. Matter 13

Vansant, E. F., Cool, P., 1997., Pillared Clay; Preparations, Characterizations, and Applications, Catalyst. Rev. Sci. Eng Chem materials, vol. 33. 265-285

Warlina R., 1985., Removal treatment detoxifications of toxic aqueous solutions, geological material chem letters online, Heavy metal in the environment part I; Cycling and characterizations., SpringerVerlags, Organometal Catalyst Letters, Publishing akatsuka., Tokyo, Japan (1995), pp. 193-207 